\title{
HTA educational outreach program and change the equation participation
}

\section{Robert Gordon}

Robert Gordon, "HTA educational outreach program and change the equation participation," Proc. SPIE 8729, Scanning Microscopies 2013: Advanced Microscopy Technologies for Defense, Homeland Security, Forensic, Life, Environmental, and Industrial Sciences, 87290B (29 May 2013); doi: $10.1117 / 12.2018284$

Event: SPIE Defense, Security, and Sensing, 2013, Baltimore, Maryland, United States 


\title{
HTA Educational Outreach Program and Change the Equation Participation
}

\author{
Robert Gordon \\ Hitachi High Technologies America, Inc., United States
}

\begin{abstract}
In this presentation, Hitachi High Technologies America (HTA) introduces its Educational Outreach Program and explains it's involvement with Change The Equation (CTEq), a nonprofit, nonpartisan, CEO-led initiative that is mobilizing the business community to improve the quality of science, technology, engineering and mathematics (STEM) learning in the United States.
\end{abstract}

Keywords: Change the Equation, scanning electron microscope, SEM, tabletop, STEM, education

\subsection{INTRODUCTION}

Change the Equation was started by five Chief Operating Officers from some of the largest companies in the U. S. along with the Carnegie Corporation of New York and the Bill and Melinda Gates Foundation in September 2010. In that time, CTEq has helped its more than 100 members connect and align their philanthropic and advocacy efforts so that they add up to more than the sum of their parts. CTEq is meant to answer President Obama's Educate to Innovate Campaign to move the U.S. to the top of the pack in science and math education over the next decade. CTEq is interested in improving STEM education for every child, with a particular focus on girls and students of color which have long been underrepresented in STEM fields. Some of the key focuses of CTEq are on scalability, sustainability, an emphasis on long term impact, support of teachers in the STEM field and encouragement of hands-on-learning. With some of the long term goals of CTEq being improving corporate member philanthropy, inspiring and capturing the imagination of America's youth, providing insight to students into STEM postsecondary and career options, and advocating change at the state and national level for STEM education, the CTEq coalition will look to speak and act as a unified voice for change in STEM education in the years to come.

Hitachi High-Technologies Corporation (Hitachi High-Tech), a global leader in the electron microscope industry, is working to inspire a new generation of achievement in science education. In loaning out its tabletop microscopes Hitachi High-Tech is tackling the problem of waning interest in science education, which is becoming a global issue throughout all industrialized nations. Hitachi High-Tech aims to become the global leader in providing high-tech solutions, and its support for science extends beyond Japan to North America, South America, and Europe.

A number of science education events are taking place across the United States to give more children the opportunity to experience the excitement and wonders of science (Figure 1). Popular among children are science classes using a tabletop scanning electron microscope to observe everyday objects around them such as fibers, plastic, plants, and insects. As a program designed to instill the wonders of science among children and cultivate their interest in it, this program's results are raising expectations not only among educational institutions and educators, but also among academic organizations, private groups, and state governments.

Twenty-four students from grades 7-12 took part in a Science Camp held in July at the University of Wisconsin-Madison. During the camp's science class, the children held an experiment where they used a TM3000 Tabletop Microscope to observe the changes that occurred when borosilicate was dipped into a zinc nitrate solution. 

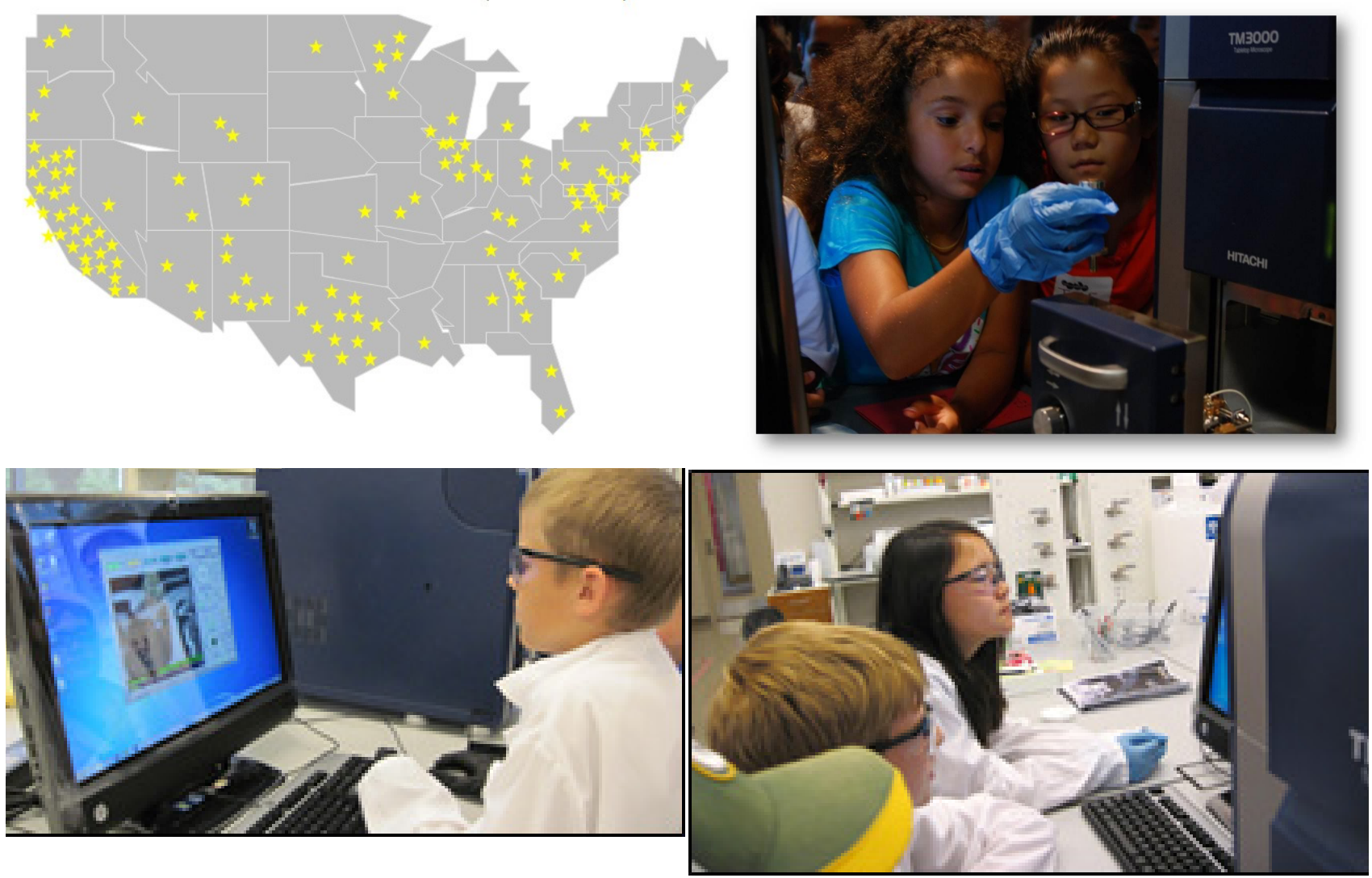

Figure 1. (left, upper) STEM activity map and students working with the tabletop SEM.

The children were using a powerful chemical, so they were required to wear protective gowns, gloves, and goggles. They were tense at first, but as their experiment and observation moved along, their eyes started to brighten and they were mesmerized by the images that appeared on their computer monitor display.

"I can't believe there are shapes like this in our world," said a girl who attended the camp, amazed at the beauty of the shapes that appeared in the micro world. One boy, a member of the local Little League baseball team, was fascinated by the tabletop microscope. "I had no idea there were devices like this," he said.

\subsection{The American Strategy: Nurture the Workforce of Tomorrow through Science and Technology}

Hitachi High Technologies America, Inc. (HTA), a subsidiary of Hitachi High-Tech, is supporting science events like this one all across the United States. HTA staff and distributors promote the tabletop microscope while also lending them to institutes of higher learning, such as junior colleges and universities, as part of the company's own independent STEM (Science-Technology-Engineering-Mathematics) Outreach Program. These grassroots level activities are the perfect tool to boost interest in science, and awareness of these activities has spread throughout the United States.

Global recognition that children were losing interest in science began to emerge around 2000. Now, the problem is regarded as a serious one that threatens to shake the industrial foundations of many globalized countries. Sensing a crisis, and regarding science and technology as a key issue, countries around the world, starting with Japan, the United States and European nations, began focusing their strengths on nurturing the workforce of the future by improving science education.

The United States has been earnest in its support of science education programs since establishing the National Science Foundation (NSF) in 1950. Each government ministry and agency has moved to implement STEM Education Programs. Under the administration of President Barack Obama, STEM education aimed at nurturing interest in the fields of science 

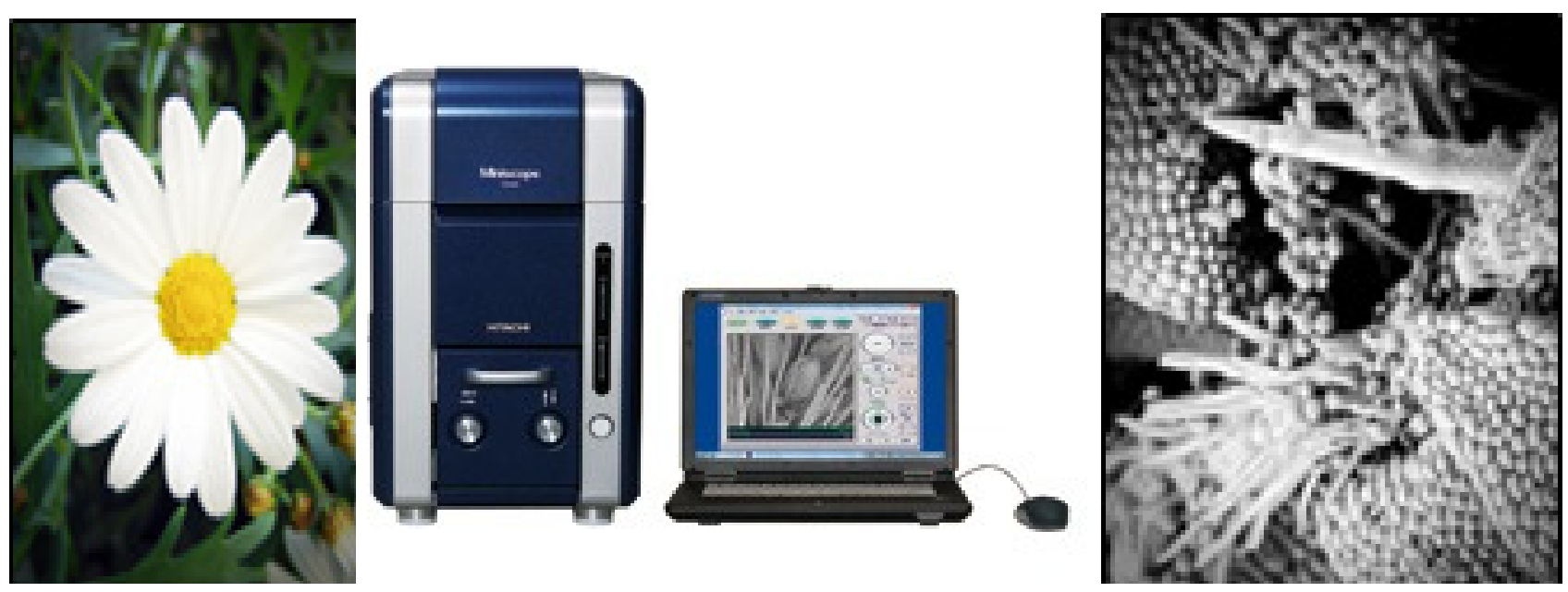

and technology, is regarded as a national strategy, with comprehensive initiatives disseminating among citizens about the need to motivate children regarding science and technology, fostering their understanding of it, and raising the overall science literacy of all Americans.

\subsection{The Tabletop Microscope: Making a Name for Itself in STEM Education}

In 2010, following on the footsteps of the Obama Administration's initiative to make America a leader in science and math, Change the Equation (CTEq), a CEO-led NPO, was started to help boost the country's STEM education. One hundred ten private companies from different industries and private and academic organizations were among the groups that volunteered to take part. Naturally, CTEq aims to improve the quality of STEM education, raise interest in science and technology among children, and educate talented people within the STEM fields. The NPO wants to act as a powerful counterweight to the growing disinterest in science and strengthen the United States.

The main role of CTEq administrators is to utilize the ideas of member companies, draw up a roadmap for the entire program, formulate strategies, evaluate each part of the program, and share successful case studies with member companies. In addition to these duties, the administrators also create guidelines for member companies, provide educational materials, and draw up plans for a variety of events. Since CTEq member companies participate from the standpoint of giving back to the community, the individual activities they engage in are all done on a voluntary basis as part of their outreach programs.

In 2011, Hitachi, Ltd. became a member of CTEq, and as a member of the Hitachi Group, Hitachi High Technologies America expanded the scope of its science education program focusing on the tabletop microscope. Support until then had centered on institutes of higher education, but moved to broader fields, first to secondary education and then onto community colleges, universities, museums, science exhibitions, and science events. It was through this cooperation with Hitachi, Ltd. and promoting CTEq's outreach program, that their STEM outreach program took shape. In fact, HTA engaged in outreach programs in 85 locations from September 2011 to June 2012. This was four times more than had been the case in the previous year.

\subsection{The Perfect Tool to Promote Science}

Hitachi High-Technologies Corporation (Hitachi High-Tech) released the revolutionary TM-1000 Tabletop Microscope more than seven years ago. Despite being an electron microscope, it was small enough to place on top of a desk, had a magnification of 10,000 times that clearly surpassed that of optical microscopes, and was simple enough that even a child could operate it after a brief demonstration. The fact that even a child could operate it was one of the reasons why the tabletop microscope has been regarded as the perfect tool for promoting science education.

Starting in Japan, Hitachi High-Tech's efforts to promote science education span the globe. Hitachi High-Tech has been using the tabletop microscope in science education events for children since 2008, when it started loaning them out to places such as the National Museum of Emerging Science and Innovation and Japan Society of Applied Physics. 


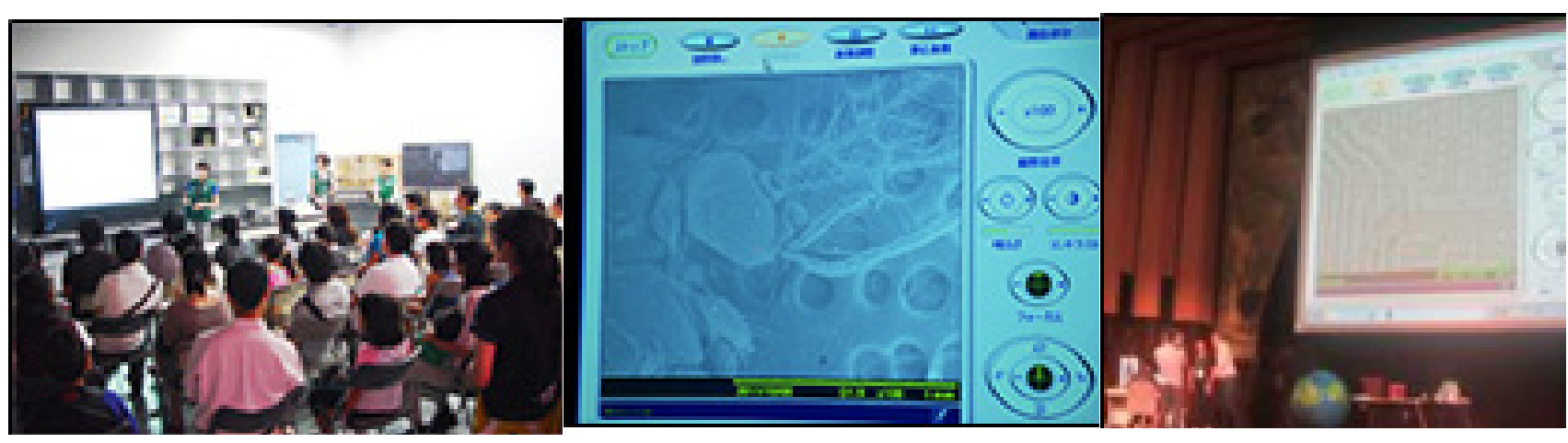

In 2010, the company successfully produced an even more compact model, the TM3000, capable of magnification up to 30,000 times. Toward the end of that same year, "nanoTruck - Meeting Place Nanoworlds" (an initiative of the German Federal Ministry of Education and Research) contacted Hitachi HighTechnologies Europe (HTE) through its project agency with the intention of initiating a cooperation.

The nanoTruck is a trailer equipped with items such as small-scale experiment devices and science-related exhibits, mostly designed for interactive use. This truck visits locations across Germany with the aim of inspiring interest in cutting-edge technology among citizens and heightening the desire to learn about science. HTE, which supports the aim of the nanoTruck, agreed to provide a tabletop microscope.

In Tokyo the following year, Hitachi High-Tech also supplied a tabletop microscope for use in the Christmas Lectures held by the British Council, Britain's official organization for promoting international exchange, where it was used to observe the microscopic structure of a semiconductor during an experiment.

\subsection{Science Education for Everyone}

Hitachi High Technologies America is currently loaning anywhere from five to 15 tabletop microscopes in the field. Five of the microscopes are set up at universities or within laboratories where they are used in relatively large events such as science camps to develop learning modules and education tools.

The remaining microscopes are managed by HTA distributors in 12 locations across 11 states, and they are mainly used within each distributor's area to support local science outreach initiatives. In these instances, students can bring their own samples for observation, learn how to interpret the results, and then organize their work in a PowerPoint presentation to share the images and findings with everyone. Regardless of how they are used, these tabletop microscopes are making a significant contribution toward improving STEM education on any given day .

HTA has another very important role within its STEM outreach program. It hosts seminars and workshops for the teachers who will provide instructions for students in science, technology, engineering, or mathematics at educational institutions. These sessions include lectures on how to operate the tabletop microscope, and also discuss successful case studies conducted through the program in the past, issues that need to be rectified, and provide data and hot topics about STEM education, all with the aim of contributing to excellence in the classroom.

In August 2012, HTA set up a special website dedicated to STEM education, http://www.inspirestemeducation.us/. The site provides information on STEM education and downloadable educational tools and learning modules for teachers.

\subsection{Getting Children Excited about the Possibilities of the Future}

"The American semiconductor market is already saturated or production has moved off-shore. HTA is think- 


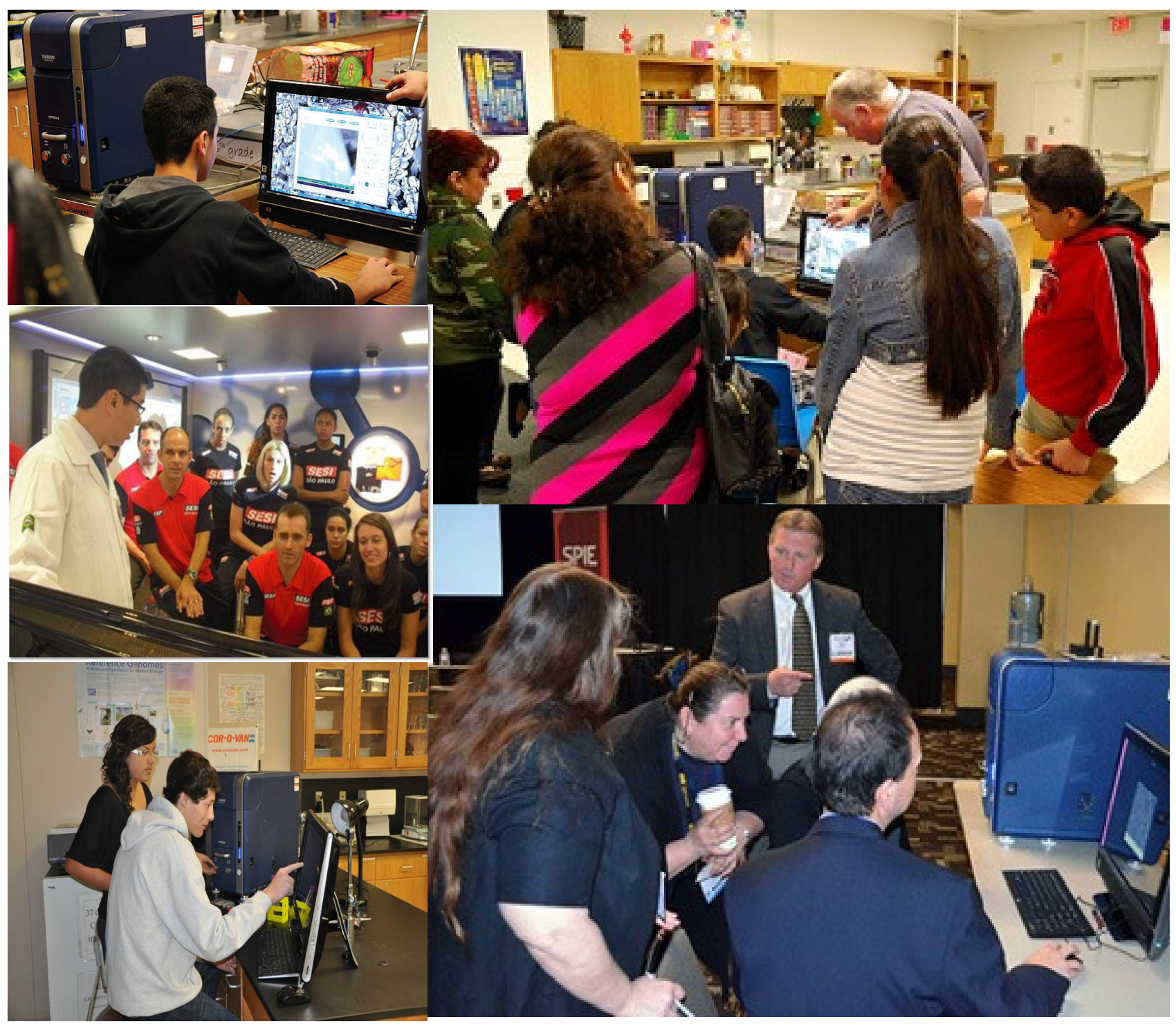

Montage of images from the STEM sessions.

ing to move the focus of its business into the analysis market for universities, research organizations, or the medical-related field. Our electron microscope business targets universities and research organizations, so we see our mission as being to put the entire company in step, strengthen our promotion of the tabletop microscope, and support science education for children," says Robert Gordon, senior executive with HTA.

Mr. Gordon is leading from the front to support science education across the United States and is in the process of making proposals about a new science education program. "One possible candidate for the next step in HTA's outreach program might be our spectrophotometers or other analytical instruments produced by Hitachi High-Tech's Naka factory."

\subsection{Conclusion}

While continuing the existing science education program using the tabletop microscope, HTA is getting ready to create even more enjoyable learning opportunities to inspire children to develop a love for science. With CERN (The European Organization for Nuclear Research) discovering the Higgs Boson particle there is a renewed interest in light particles, starting with photons. Spectrophotometers that can identify light wavelength in liquids or solids are a timely tool for science education programs. Mr. Gordon thinks that they could be used to provide children with a new and exciting experience. 


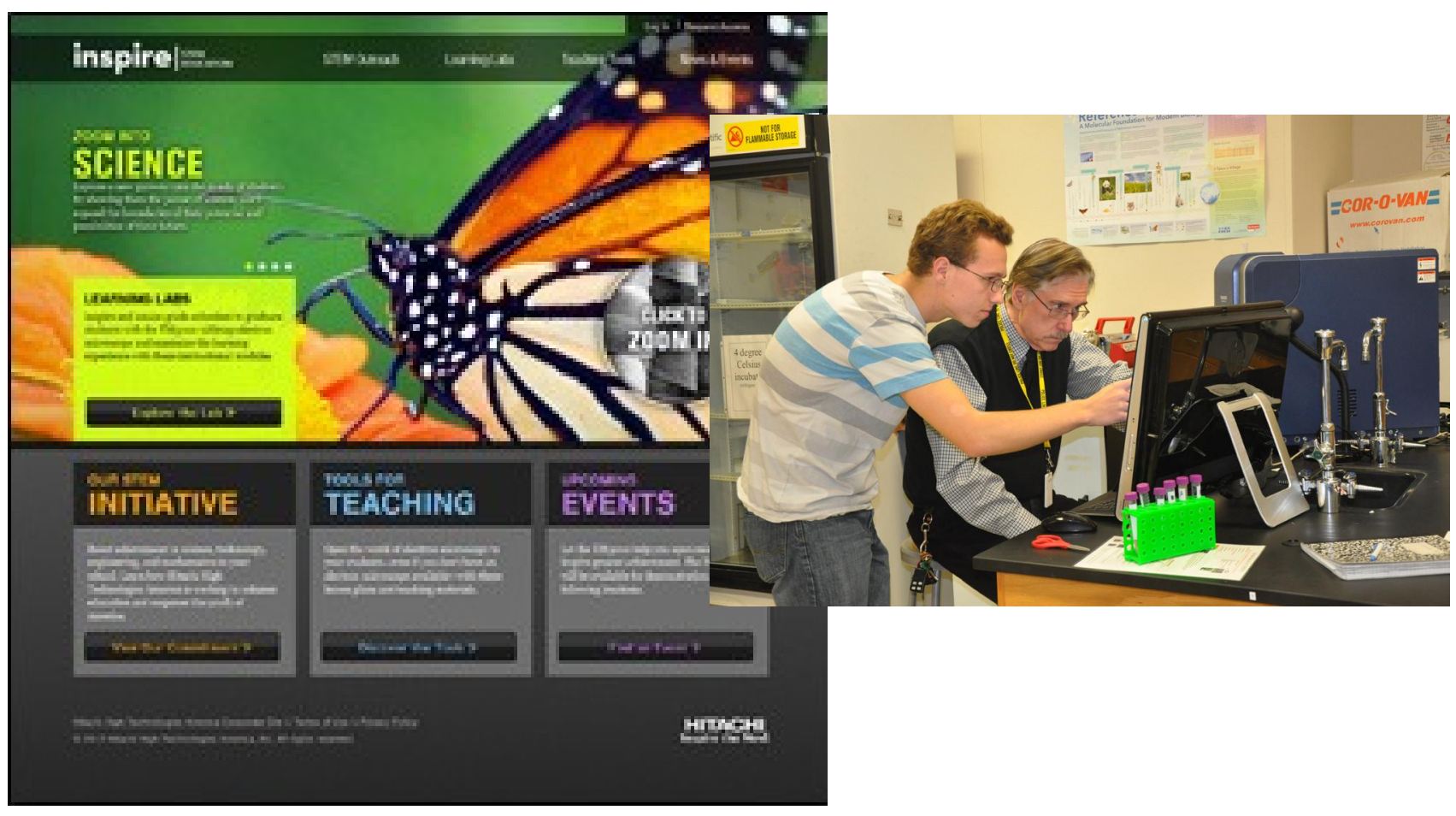

Speaking of American children, it's a tradition for them to head to summer camp during summer holidays. While some kids love the outdoors, others choose to go to a sports camp. However, for children who are charmed by the appeal of peering through a tabletop microscope to gaze at the micro world, it is only natural that they go to a science camp. Considering this, maybe one good way to improve science education would be to ditch textbooks, get out of the classroom, and draw children into a world that will be exciting for them. And for HTA, an outreach program featuring spectrophotometers could be the next great thing to light up the lives of children. 